\title{
The Respiratory System Has a Resourceful Defense Organization; A Review
}

\author{
IYAWE, V I; *OMOROGIUWA, A \\ Department of Physiology, School of Basic Medical Sciences, College of Medical Sciences, University of Benin, Benin City, Nigeria \\ *Corresponding Author Email: ask4ade2006@yahoo.com; arthur.omorogiuwa@uniben.edu \\ Tel: +2347039460340
}

\begin{abstract}
The respiratory system is essentially made up of a channel which starts from the nostrils and ends in the alveoli. Although it is primarily adapted for gaseous exchange, it has a resourceful defense organization which traverses the nose to the alveoli. Defense structures include fine hairs, mucous membrane in the nostrils, ciliated epithelium in the tracheobronchial tree and immune cells in all parts of the respiratory tract to the alveoli. Thus in studying the anatomy and physiology of respiratory system ,the non-respiratory function of defense should attract adequate attention as partial or whole dysfunction of the respiratory tract not only has a potential capacity of compromising gaseous exchange but also attenuating the functional defense structures of the respiratory system. This review is thus aimed at bringing to lime light the defense functions of the respiratory system being one of the gateways to the entire body system. The review shows that the respiratory system is very versatile in its defense functions and this should be kept in view by Respiratory Physicians when managing respiratory conditions as this will ultimately brighten the overall outcome.
\end{abstract}

\section{DOI: https://dx.doi.org/10.4314/jasem.v22i11.24}

Copyright: Copyright $(\odot) 2018$ Iyawe and Omorogiuwa. This is an open access article distributed under the Creative Commons Attribution License (CCL), which permits unrestricted use, distribution, and reproduction in any medium, provided the original work is properly cited.

Dates: Received: 17 November 2018; Revised: 26 November 2018; Accepted 30 November 2018

Keywords: Respiratory system, Gaseous exchange, Defense function

The human respiratory system is functionally structured for the utilization of atmospheric oxygen for its day to day metabolic activities and continued existence. The utilization of this "currency" called oxygen by tissues ultimately produces $\mathrm{CO}_{2}$ which is expelled into the atmosphere. The atmosphere is thus saddled with other constituents other than oxygen in such a way that each day, humans are exposed to varying quantity of millions of bioaerosols including whole organism with dentrimental effects (Prussin and Marr, 2015). The quantity of bioerosols that one is exposed to, is a function of the particular environmrnt, for instance in one of the few studies of concentrations of total bacteria and viruses in indoor air, Prussin et al. (2015) found virus-like and bacteria-like particle concentrations of $\sim 10^{5}$ and $\sim 10^{6}$ particles $\mathrm{m}^{-3}$ in various indoor environments and outdoor air, respectively. Shelton et al. (2002) measured an average viable airborne fungi concentration of 80 colony-forming units $(\mathrm{CFU}) \mathrm{m}^{-3}$ in samples collected from schools, hospitals, residences, and industrial buildings; however, in some instances concentrations were as high as $10^{4} \mathrm{CFU} \mathrm{m}{ }^{-3}$. To accommodate this atmospheric contaminants that is inevitably inspired the respiratory tract is encumbered with physical and cellular components that enables it perform defense functions. The review is aimed at bringing to lime light the defense functions of the respiratory system being one of the gateways to the entire body system.

\section{MATERIALS AND METHOD}

The literatures for this review where those published between 1962 to 2018 and they were articles from journals indexed in Ajol, PubMed, Medline, Embase, Index Medicus, Index Copernicus etc. Key words such as respiratory, functions, gaseous, exchange, immunity were used to facilitate the search for this review article.

\section{RESULTS AND DISCUSSION}

Defense Functions: The defense functions of the respiratory system include (i) passive innate response or functional anatomy of the respiratory system in relation to defense function (ii) active innate response or response based on defensins, cathelicidins, alveolar macrophages, antimicrobial activity of surfactant/lung fluids (iii) Adaptative immune response or response based on $\mathrm{T}$ and $\mathrm{B}$ lymphocytes

Passive innate response or functional anatomy of the respiratory system in relation to defense function: The functional anatomy of the upper respiratory tract includes a very moist mucus membrane and an aerodynamic fibre complex which is made up of fine hairs and cilitaed epithelial cells. The fine hairs work

*Corresponding Author Email: ask4ade2006@yahoo.com; arthur.omorogiuwa@uniben.edu

Tel: +2347039460340 
in synergy with the moist mucus membrane to trap foreign bodies. This action is further potentiated by the presence of ciliated epithelium with the cilia beating towards the pharynx so that foreign particles that are proximal to the pharynx can be swallowed. However, some foreign particles can be voluntarily navigated through the oropharynx into the mouth and expectorated out as mucus mixed with it (phlegm). This highly effective mechanism of mucocilliary clearance of small particles works by a complex interaction between cilia and mucus forming a raft on the top of the cilia with an appearance of a "bunch of matchstick" on electron microscopy. However, a number of factors may reduce mucociliary clearance by interfering with ciliary function or by causing actual ciliary damage. A defect in the mucociliary clearance can be acquired through pollutants, cigarette smoke, anesthetic agents (local and general), bacterial products and viral injection. Studies have shown that $2.46 \%$ of workers in a cement factory in Benin who were also chronic smokers were diagnosed of chronic bronchitis (Alakija et al., 1990). On the other hand, it can be genetic as seen Ciliopathies which are inherited human disorders caused by both motile and non-motile cilia dysfunction that form an important and rapidly expanding disease category ( Mitchison and Valente, 2017). A defect in mucociliary clearance whether acquired or genetic ultimately results in respiratory tract infections. Mucus combines with foreign particles that are distal to the pharynx to be blown out as phlegm mixed with the foreign particles. The cough reflex potentiates the mucociliary clearance mechanism being a protective reactive expulsion of plegm through the mouth after a threshold irritation of the gloso-pharyngeal and vagus nerves in the lower respiratory tract. Coughing is an important defensive reflex that enhances clearance of secretions and particulates from the airways and protects from aspiration of foreign materials occurring as a consequence of aspiration or inhalation of particulate matter, pathogens, accumulated secretions, postnasal drip, inflammation, and mediators associated with inflammation (Mario et al., 2012). The expression of phlegm from productive cough is defensive as agianst the non-productive cough which could be a complication of some medications such as angiotensin converting enzyme (ACE) inhibitor. The hypothetical pathophysiology is the inhibition of the degradation of protussive mediators such as bradykinin and substance $\mathrm{P}$ by Angiotensin Converting Enzyme (Dicpinigaitis, 2006), thus these substances remain in the upper respiratory tract or the lungs causing persistent cough. This observation is consistent with the fact that hypertensives treated with other antihypertensive drugs which do not affect bradykinin metabolism is spared of this disturbing cough. In addition to the protective mucociliary mechanism and the cough reflex, the nasal cavity is supplied by sensory nerve endings of the trigeminal nerve which is snsitive to irritants. The inhalation of an irriatant initiates the sneezing reflex. Sneezing (sternutation) is a coordinated protective respiratory reflex which occurs due to stimulation of the upper respiratory tract, particularly the nasal cavity (Murat and Cemal, 2009). A sneeze is a protective reflex expressed as the expulsion of air from the lungs through the mouth and nose after an adequate threshold irritation of the nasal mucosa. Other important protective functions of mucus include, dilution of noxious substances, lubrication of the airways and humidification of inspired air

Active innate response based on defensins, cathelicidins, alveolar macrophages and antimicrobial activity of surfactant/lung fluids: Defesins and Cathelicidins: The fluids lining the lungs contain defensive proteins, such as complement, immuoglobulin, defensins, cathelicidines (powerful antibacterial peptides) and a variety of antiproteinases. Among the defensins, the $\beta$-defensin which is widely expressed in the epithelial lining of the respiratory tract and other epithelial linings of the body is of utmost interest. They have a broad spectrum of antibacterial, antifungal and antiviral activity just like the peptide cathelicidin LL-37 which is also expressed in the epithelial cells of the respiartory tract (De Smet and Contreras, 2005). In addition, defensins recruit inflamamatory cells and promote innate and adaptive immune response (Tecle et al., 2010).

Pulmonary Alveolar Macrophages (PAM): Alveolar macrophages are multipotent cells located at the interphase between the air and the lung tissue and demonstrate a formidable array of mechanisms with which they recognize and phagocytose bacteria and other foreign particles. In addition to their first line phagocytic defense against microbial invasion in the lower respiratory tract, they play a role in regulating inflammatory reaction in the lung by acting as chemoattractants for invading cells and stimulating local cells to build up proinflammatory milieu (Niesler et al., 2014). Phagocytosis is categorized into opsonic and nonopsonic mechanisms and the pulmonary alveolar macrophages utilize nonopsonic, instead of Fc or complement receptor-mediated, phagocytosis to eliminate pathogens such as $P$. aeruginosa from the lung (Cheung et al., 2000). The alveolar macrophages exert important scavenging function in the clearance of dead bacteria and other cells during the after math of an infection and inflammation. However excessive or uncontrolled release of these powerful macrophage products may cause disordered inflammation or 
scarring responses, which are likely to be important in the pathogenesis of a variety of inflammatory disease like asthma

Antimicrobial Activity of Surfactant/Respiratory Fluids: Pulmonary surfactant contains four associated surfactant proteins (SP); SP-A, SP-B, SP-C and SP-D. Whereas SP-A and SP-D are hydrophilic, the SP-B and SP-C are highly hydrophobic (Cabre et al., 2018). The hydrophobic surfactant proteins are members of the collectins family which have in common an $\mathrm{NH}_{2}-$ terminal collagen-like region and $\mathrm{C}$-terminal lectin domain that binds viral and bacterial phospholipids in a calcium dependent manner (Crouch and Wright, 2001; Crouch et al., 2000; Augusto et al., 2001) and exhibit cationic channel activity when inserted in planar surfactant lipid bilayer (Parra et al., 2013).

The collectins play a role in innate and adaptive immunity (Han and Mallampalli, 2015). Studies have shown that SP-A and SP-D have immunomodulating roles in humans as well as a broad range of antimicrobial activity against bacteria, fungi and viruses (LeVine and Whitsett, 2001; McCormack and Whitsett, 2002). The mechanism of antimicrobial activity is suggested to be through the formation of aggregates with the pathogen to inhibit cellular invasion, enhance phagocytosis and alter inflammation such as production of reactive oxygen species or cytokines expression (McCormack and Whitsett, 2002). Also, SP-A and SP-D increases membrane permeability of the microbes with direct antibacterial activity on Escherichia coli, Klebsiella pneumoniae, and Enterobacter aerogenes (Wu et al., 2003) and antifungal activity on Histoplasma capsulatum (McCormack et al., 2003).

In humans there exist two genes, SP-A1 and SP-A2 that encode for SP-A1 and SP-A2 proteins, respectively (Floros et al., 2003). This suggests a possibility that there may be human subpopulations with differential vulnerabilities to microbial infection based on these SP-A isoforms. More recently, it was found that the hydrophilic proteins SP-A and SP-D play a major role in host defense by inhibiting bacterial growth, facilitating bacterial uptake by host cells, and aggregating and opsonizing pathogens (Nayak et al., 2012). The hydrophobic protein SP-B also appears to have some antimicrobial activity (Mulugeta and Beers, 2006; Blanco and Pérez-Gil, 2007; Perez-Gil and Weaver, 2010). Mixed samples of respiratory fluid obtained from the nose by mechanical or chemical stimulation (Cole et al., 1999; Raphael et al., 1989), or as sputum from patients with chronic bronchitis (Brogan et al., 1975, Harbitz et al., 1984, Kotlar et al., 1980) indicate that lysozyme and lactoferrin are the most abundant antimicrobial proteins of airway secretions, at approximately $0.11 \mathrm{mg} / \mathrm{ml}$. These antimicrobial proteins are derived predominantly from serous cells of submucosal glands but also from surface epithelium of the respiratory tract (Dubin et al., 2004).

Adaptative immune response or response based on $T$ and B lymphocytes: Adaptive immune responses in the airways are mediated by $\mathrm{B}$ cells and $\mathrm{T}$ cells that express highly evolved and specific receptors. In some cases, such as autoimmune diseases or inflammatory diseases caused by excessive exposure to self- or foreign antigens, these same immune cells can cause disease by virtue of overly vigorous responses (Kato et al., 2013) . Lymphocyte are present in the various compartments of the respiratory tract and they play their role of defense against bacteria and viruses. Although the ratio of $\mathrm{T}$ helper cells to $\mathrm{T}$ cytotoxic cells varies from compartment to compartment. About $10 \times 10^{9}$ lymphocytes have been calculated as the lymphocyte count for lung interstitium (mucocilliary epithelium of the trachea and bronchi) of healthy individuals and a vast majority of such lymphocytes express CD45RO marker which is often an indictor for memory lymphocytes (Pabst and Tschernig, 1995; Upham et al., 1994 ). These lymphocytes are mainly T-cells with CD $8^{+}$cytotoxic cells by far outweighing the CD $4^{+}$helper cells (Pabst and Tschernig, 1995). B lymphoctes are hardly found in the bronchial epithelium; however, $18 \mathrm{~T}$ lymphocytes per 100 epithelial cells were recorded in healthy individuals (Fournier et al., 1989). Conversely, more T helper than $\mathrm{T}$ cytotoxic cells are found in the lamina propria and a considerable number of lymphocytes express surface immunoglobulins of about $70 \% \mathrm{~T}$ and $10 \% \mathrm{~B}$ lymphocytes (Hunninghake et al., 1981). One of the primary functions of $\mathrm{B}$ cells in the airways is the production of immunoglobulins, both within the parenchyma as well as for export to the mucosal surface of the airway (Kato et al., 2013). In particular, airway B cells, like those in the gut, produce polymeric forms of IgA and IgM that are structurally maintained by the joining or J chain. In humans lacking IgA, there is a relatively modest compromise in respiratory immunity because IgM production, and possibly IgD, is thought to compensate in the absence of $\operatorname{IgA}$ (Johansen et al., 2005).

Conclusion: The respiratory tract is endowed with macroscopic protective structures and microscopic defense cells that curtail contaminants and pathogens coming through the open end of respiratory tract thus ensuring a sterile air for gaeous exchange. This should be kept in view by Respiratory Physicians when 
managing respiratory conditions as this will ultimately brighten the overall outcome.

\section{REFERENCES}

Afzelius, BA (1976). A human syndrome caused by immotile cilia. Science. 193: 317-319.

Alakija, W; Iyawe, VI; Jarike, LN; Chiwuzie, JC (1990). Ventilatory function of workers at okpella cement factory in Nigeria. West African Journal of Medicine. 9(3): 187-192

Augusto, L; Le Blay, K; Auger, G; Blanot, D; Chaby, R.(2001). Interaction of bacterial lipopolysaccharide with mouse surfactant protein C inserted into lipid vesicles. Am. J. Physiol. 281:L776-L785

Blanco, O; Pérez-Gil, J(2007). Biochemical and pharmacological differences between preparations of exogenous natural surfactant used to treat Respiratory Distress Syndrome: role of the different components in an efficient pulmonary surfactant. Eur J Pharmacol. 568:1-15.

Brogan, TD; Ryley, HC; Neale, L; Yassa, J. (1975). Soluble proteins of bronchopulmonary secretions from patients with cystic fibrosis, asthma, and bronchitis. Thorax 30:72-79.

Cabré, EJ; Martínez-Calle, M; Prieto, M; Fedorov, A; Olmeda, B; Loura, LMS; Pérez-Gil, J (2018). Homo- and hetero-oligomerization of hydrophobic pulmonary surfactant proteins SP-B and SP-C in surfactant phospholipid membranes. The Journal of Biological Chemistry. 293: 93999411

Cheung, DOY; Halsey, K; Speert, DP (2000). Role of Pulmonary Alveolar Macrophages in Defense of the Lung against Pseudomonas aeruginosa. infect Immun. 68(8): 4585-4592.

Cole, AM; Dewan P; Ganz, T. (1999) Innate antimicrobial activity of nasal secretions. Infect. Immun. 67: 3267-3275

Crouch, E; Hartshorn, K; Ofek, I (2000). Collectins and pulmonary innate immunity. Immunol Rev. 173:52-65.

Crouch, E; Wright, JR (2001). Surfactant proteins a and $\mathrm{d}$ and pulmonary host defense. Annu Rev Physiol. 63:521-554.

Crouch, EC (1998). Collectins and pulmonary host defense. Am J Respir Cell Mol Biol. 19:177-201.
De Smet, K; Contreras R (2005). Human antimicrobial peptides: defensins, cathelicidins and histatins. Biotechnol Lett. 27(18):1337-47.

Dicpinigaitis, PV (2006). Angiotensin-Converting Enzyme Inhibitor-Induced Cough. Chest 129(1): 169S-173S

Dubin, RF; Robinson, SK; Widdicombe, JH (2004). Secretion of lactoferrin and lysozyme by cultures of human airway epithelium. Am J Physiol Lung Cell Mol Physiol. 286(4):L750-5

Floros, J; Wang, G; Mikerov, AN (2009). Genetic complexity of the human innate host defense molecules, surfactant protein A1 (SP-A1) and SPA2-impact on function. Crit Rev Eukaryot Gene Expr. 19:125-137.

Fournier, M; Lebargy, F; Le Roy Ladurie, F; Lenormand, E; Pariente, R (1989). Intraepithelial T-lymphocyte subsets in the airways of normal subjects and of patients with chronic bronchitis. Am Rev Respir Dis 140:737-742

Han, S; Mallampalli, RK (2015).The Role of Surfactant in Lung Disease and Host Defense against Pulmonary Infections.Ann Am Thorac Soc.12(5):765-74.

Harbitz, O; Jenssen, AO; Smidsrod O (1984). Lysozyme and lactoferrin in sputum from patients with chronic obstructive lung disease. Eur. J. Respir. Dis. 65:512-520.

Hauschildt, S; Kleine, B (1995). Bacterial stimulators of macrophages. Int Rev Cytol. 161:263-331

Hunninghake, GW; Kawanami, O; Ferrans, VJ; Young, RC; Roberts, WC; Crystal, RG (1981). Characterization of the inflammatory and immune effector cells in the lung parenchyma of patients with interstitial lung disease. Am Rev Respir Dis. 123:407-412

Israili, ZH, Hall, WD (1992). Cough and angioneurotic edema associated with angiotensinconverting enzyme inhibitor therapy. A review of the literature and pathophysiology. Ann Intern Med. 117:234-242

Johansen, F; Baekkevold, ES; Carlsen, HS; Farstad, IN; Soler, D; Brandtzaeg, P (2005). Regional induction of adhesion molecules and chemokine receptors explains disparate homing of human $\mathrm{B}$ 
cells to systemic and mucosal effector sites: dispersion from tonsils. Blood. 106:593-600

Kartagener, M; Stucki P(1962). Bronchiectasis with situs inversus. Arch Pediatr 1962; 79: 193-207

Kato, A; Hulse, KE; Tan, BK; Schleimer, RP (2013). B lymphocyte lineage cells and the respiratory system. J Allergy Clin Immunol. 131(4): 933957.

Kotlar, HK; Harbitz, O; Jenssen, AO; Smidsrod, O. (1980) Quantitation of proteins in sputum from patients with chronic obstructive lung disease. II. Determination of albumin, transferrin, alpha1acid glycoprotein, IgG, IgM, lysozyme and C3complement factor. Eur. J. Respir. Dis. 61:233239

LeVine, AM; Whitsett, JA (2001). Pulmonary collectins and innate host defense of the lung. Microb. Infect. 2001;3:161-166.

LeVine, AM; Bruno, MD; Huelsman, KM; Ross, GF; Whitsett, JA; Korfhagen, TR (1997). Surfactant protein A-deficient mice are susceptible to group B streptococcal infection. J Immunol. 158:43364340

LeVine, AM; Gwozdz; J, Stark, J; Bruno, M; Whitsett, J; Korfhagen, T (1999). Surfactant protein-A enhances respiratory syncytial virus clearance in vivo. J Clin Invest. 103:1015-1021

McCormack, FX; Gibbons, R; Ward, S; Kuzmenko, A; Wu, H; Deepe Jr, GS (2003). Macrophageindependent fungicidal action of the pulmonary collectins. J Biol Chem. 278:36250-36256

McCormack, FX; Whitsett, JA (2002). The pulmonary collectins, SP-A and SP-D, orchestrate innate immunity in the lung. J. Clin. Invest. 109:707712

Mitchison, HM1; Valente, EM (2017). Motile and non-motile cilia in human pathology: from function to phenotypes. J Pathol. 241(2):294309

Mulugeta, S; Beers, MF (2006). Surfactant protein C: its unique properties and emerging immunomodulatory role in the lung. Microbes Infect. 8:2317-2323
Murat, S; Cemal, C (2009). Sneeze reflex: facts and fiction. Therapeutic advances in respiratory diseases 3(3): 131-141

Nayak, A; Dodagatta-Marri, E; Tsolaki, AG; Kishore, $\mathrm{U}$ (2012). An insight into the diverse roles of surfactant proteins, SP-A and SP-D in innate and adaptive immunity. Front Immunol. 3:131

Niesler, U1; Palmer, A; Radermacher, P; HuberLang, MS (2014). Role of alveolar macrophages in the inflammatory response after trauma. Shock. 42(1):3-10

Noone, PG; Zariwala, M; Knowles, MR (2006). Primary ciliary dyskinesia. In: Runge $\mathrm{M}$, Patterson C, eds. Principles of Molecular Medicine. Totowa, Humana Press. pp. 239-250

Pabst, R; Tschernig T (1995). Lymphocytes in the lung: an often neglected cell Numbers, characterization and compartmentalization. Anat Embryol. 192 (4):293-299

Parra, E; Alcaraz, A; Cruz, A; Aguilella, VM; Pérez Gil, J (2013). Hydrophobic pulmonary surfactant proteins SP-B and SP-C induce pore formation in planar lipid membranes: evidence for proteolipid pores. Biophys. J. 104, 146-155

Perez-Gil, J; Weaver, TE (2010). Pulmonary surfactant pathophysiology: current models and open questions. Physiology (Bethesda). 25:132141

Polverino, M; Polverino, F; Fasolino, , et al (2012). Anatomy and neuro-pathophysiology of the cough reflex arc. Multidiscip Respir Med.7:5. 10.1186/2049-6958-7-5

Prussin, AJ $2^{\text {nd }}$; Marr, LC (2015). Sources of airborne microorganism in the built environment. Microbiome 3:78

Prussin, AJ 2 ${ }^{\text {nd }}$; Garcia, EB; Marr, LC (2015). Total concentrations of virus and bacteria in indoor and outdoor air. Environ Sci Technol Lett. 2:84-88

Raphael, GD; Jeney, EV; Baraniuk, JN; Kim, I; Meredith, SD; Kaliner, MA (1989). Pathophysiology of rhinitis. Lactoferrin and lysozyme in nasal secretions. J. Clin. Invest. 84: 1528-1535

Shelton, BG; Kirkland, KH; Flanders, WD; Morris, GK (2002). Profiles of airborne fungi in buildings 
and outdoor environments in the United States. Appl Environ Microb. 68:1743-1753

Soutar, CA (1976). Distribution of plasma cells and other cells containing immunoglobulin in the respiratory tract of normal man and class of immunoglobulin therein. Thorax. 31:158-166

Tecle, T; Tripathi, S; Hartshorn, KL (2010). Review: Defensins and cathelicidins in lung immunity. Innate Immun; 16(3):151-9
Upham, JW; McMenamin, C; Schon-Hegrad, MA; Robinson, BWS; Holt, PG (1994). Functional analysis of human bronchial mucosal $\mathrm{T}$ cells extracted with interleukin-2. Am J Respir Crit Care Med 149:1608-1613

Wu, H; Kuzmenko, A; Wan, S; Schaffer, L; Weiss, A; Fisher, JH; Kim, KS; McCormack, FX (2003). Surfactant proteins A and D inhibit the growth of gram-negative bacteria by increasing membrane permeability. J Clin Invest. 111:1589-1602. 